\title{
Sobre a noção de Situação Didática Olímpica aplicada ao contexto das Olimpíadas
}

\section{Internacionais de Matemática}

\author{
Paulo Vitor da Silva Santiago 1 \\ Universidade Federal do Ceará - UFC, Programa de Pós-Graduação Profissional em Ensino de
} Ciências e Matemática, Fortaleza, CE, Brasil

Francisco Régis Vieira Alves ${ }^{2} \mathbb{D}$

Instituto Federal de Educação, Ciência e Tecnologia do Ceará - IFCE, Programa de Pós-Graduação em Ensino de Ciências e Matemática, Fortaleza, CE, Brasil

\author{
Beatriz Maria Pereira Maia ${ }^{3}$ \\ Universidade Federal do Ceará - UFC, Programa de Pós-Graduação Profissional em Ensino de \\ Ciências e Matemática, Fortaleza, CE, Brasil
}

\begin{abstract}
Resumo
O presente artigo apresenta uma ordem teórico-conceitual específico de uma estruturação da investigação em Didática da Matemática com a finalidade de mostrar uma discussão e a oportunidade do alcance de conhecimentos didático-metodológicos envolvendo o ensino de Geometria Plana por meio de Problemas Olímpicos obtidos das avaliações da Olimpíada Internacional de Matemática. O objetivo do trabalho é realizar uma Engenharia Didática pretendendo a estruturação de uma Situação Didática Olímpica, com ênfase no ensino de Geometria Plana, com o apoio do software educacional GeoGebra como recurso tecnológico com o propósito de proporcionar a compreensão de novas resoluções aos alunos por meio dos comandos e visualização das figuras expostas na situaçãoproblema didática olímpica. Foi utilizada a metodologia de Michèle Artigue (1988), a Engenharia Didática enumerado nas suas primeiras fases: Análises preliminares e Concepção e Análise a priori da situação didática, com dedicação à concepção e a modelização de figuras planas de uma situaçãoproblema olímpica em acréscimo com a Teoria das Situações Didáticas de Guy Brousseau (1986) e o software educacional GeoGebra como recurso tecnológico colaborando na construção junto aos
\end{abstract}

Submetido em: 17/01/2021

Aceito em: 27/04/2021

Publicado em: 08/06/2021

${ }^{1}$ Mestrando em Ensino de Ciências e Matemática pela Universidade Federal do Ceará - UFC, Professor temporário da Secretaria de Educação do Município de Quixeramobim - SEDUC, Rodovia do Algodão, S/N, CEP: 63800-000, Monteiro de Morais - Quixeramobim - Ceará - Brasil. E-mail: pvitor60@ hotmail.com.

${ }^{2}$ Doutor em Educação pela Universidade Federal do Ceará, Bolsista de produtividade do CNPQ - PQ2. Professor permanente do Programa de Pós-Graduação em Ensino de Ciências e Matemática do IFCE, Professor permanente do Programa de Pós-Graduação em Ensino de Ciências e Matemática da Universidade Federal do Ceará. Professor permanente do Programa de Pós-Graduação do Mestrado Profissional em Educação profissional tecnológica. Líder do Grupo de Pesquisa CNPQ Ensino de Ciências e Matemática. Página pessoal: https://ifce.academia.edu/RegisFrancisco/Journal-Articles. Endereço para correspondência: Avenida Treze de Maio, 2081, 60040-215, Fortaleza, Ceará, Brasil. E-mail: fregis@ ifce.edu.br.

${ }^{3}$ Mestranda em Ensino de Ciências e Matemática pela Universidade Federal do Ceará - UFC. Professora da rede privada no município de Fortaleza. E-mail: beatrizpmaia@gmail.com 
comandos operacionais e a visualização da figura. Essa proposta tem importância em uma Situação Didática Olímpica para os professores de matemática promover momentos de interação que favoreceram a execução em sala de aula ou na preparação de procedimentos para a Olimpíada Internacional de Matemática, ou seja, para um melhor planejamento e na aprendizagem metodológica aplicada no ambiente escolar.

Palavras-chave: Engenharia Didática; Teoria das Situações Didáticas; IMO.

\title{
On the notion of Olympic Didactic Situation applied to the context of the International Mathematical Olympiad
}

\begin{abstract}
The present article presents a specific theoretical-conceptual order of a structuring of research in Mathematics Didactics with the purpose of showing a discussion and the opportunity of reaching didactic-methodological knowledge involving the teaching of Plane Geometry through Olympic Problems obtained from the evaluations of the International Mathematical Olympiad. The objective of the work is to carry out a Didactic Engineering aiming at the structuring of an Olympic Didactic Situation, with emphasis on the teaching of Plane Geometry, with the support of the educational software GeoGebra as a technological resource with the purpose of providing the understanding of new resolutions to the students through the commands and visualization of the figures exposed in the Olympic didactic problem-situation. The methodology of Michèle Artigue (1988) was used, the Didactic Engineering listed in its first phases: Preliminary Analysis and Design and Analysis a priori of the didactic situation, with dedication to the design and modeling of plane figures of an Olympic problem-situation in addition to the Theory of Didactic Situations of Guy Brousseau (1986) and the educational software GeoGebra as a technological resource collaborating in the construction along with the operational commands and the visualization of the figure. This proposal has importance in an Olympic Didactic Situation for mathematics teachers to promote moments of interaction that favored the execution in the classroom or in the preparation of procedures for the International Mathematical Olympiad, i.e., for better planning and methodological learning applied in the school environment.
\end{abstract}

Keywords: Didactic Engineering; Theory of Didactic Situations; IMO.

\section{Sobre la noción de situación didáctica olímpica aplicada al contexto de la Olimpiada Internacional de Matemáticas}

\section{Resumen}

El presente artículo presenta un orden teórico-conceptual específico de una estructuración de la investigación en Didáctica de la Matemática con el propósito de mostrar una discusión y la oportunidad del alcance del conocimiento didáctico-metodológico que involucra la enseñanza de la Geometría Plana por medio de Problemas Olímpicos obtenidos de las evaluaciones de la Olimpiada Matemática Internacional. El objetivo del trabajo es realizar una Ingeniería Didáctica pretendiendo la estructuración de una Situación Didáctica Olímpica, con énfasis en la enseñanza de la Geometría Plana, con el apoyo del software educativo GeoGebra como recurso tecnológico con el fin de proporcionar la comprensión de nuevas resoluciones a los estudiantes a través de los comandos y visualización de las figuras expuestas en la situación-problema didáctica olímpica. Se utilizó la metodología de Michèle Artigue (1988), la Ingeniería Didáctica enumerada en sus primeras fases: Análisis Preliminar y Diseño y Análisis a priori de la situación didáctica, con dedicación al diseño y modelado de figuras planas de una situación problemática olímpica además de la Teoría de las 
Situaciones Didácticas de Guy Brousseau (1986) y el software educativo GeoGebra como recurso tecnológico contribuyendo a la construcción con los comandos operativos y la visualización de la figura. Esta propuesta tiene importancia en una Situación Didáctica Olímpica para que los profesores de matemáticas promuevan momentos de interacción que favorezcan la implementación en el aula o en la preparación de procedimientos para la Olimpiada Matemática Internacional, es decir, para una mejor planificación y aprendizaje metodológico aplicado en el ámbito escolar.

Palabras clave: Ingeniería Didáctica; Teoría de Situaciones Didácticas; OMI.

\section{Introdução}

As olimpíadas de Matemática nos modelos atuais são disputadas desde 1894, quando foram organizadas em competições que começaram a ser famosas na Hungria. Com isso, o aumento é crescente na sua reputação, e a partir disso, competições similares começaram a surgir pelo leste europeu, culminando em diversos outros países participantes. Em sua primeira edição a Olimpíada Internacional de Matemática (International Mathematical Olympiad - IMO), realizada no ano de 1959, na cidade de Bucareste - Romênia, com a participação de alguns países que formavam a Cortina de Ferro: Bulgária, Hungria, Polônia e Romênia, além de outros, hoje extintos, União Soviética (URSS), Alemanha Oriental e Tchecoslováquia. Durante o percurso da IMO, o número significativo de países foi aumentando consideravelmente, chegando a 105 nações que participaram da olimpíada em 2020, incluindo o Brasil que teve sua primeira participação em 1979, e desde então, tem obtido resultados cada vez mais importantes.

Á vista disso, tem-se pensando então as diferentes metodologias que poderão ser levadas para a sala de aula, pretendendo uma melhor compreensão dos estudantes (ALVES, 2018, 2016). Rodrigues e Alves (2019), descrevem que a aprendizagem emprega situações do cotidiano unido com materiais didáticos adequados, instigam os alunos no processo de ensino e aprendizagem, transformando-os mais compreensíveis aos novos conhecimentos.

Dessa maneira, a problemática do referido artigo é a forma e a abordagem como o professor se utiliza dessa preparação disponibilizada pela OBM, uma vez que o aluno tem a oportunidade de contextualizar os conteúdos e prolongar suas curiosidades, despertando-lhe a vontade de aprender, conforme Alves (1994), descreve que a "vivência do corpo humano: só é armazenado na memória aquilo que é objeto de desejo para aprender”. Sendo a sua “[...] tarefa primordial do professor: seduzir o aluno para que ele deseje e, desejando, aprenda" (ALVES, 1994, p.70).

Diante do contexto, a justificativa se introduz na proposta de trabalhar com olimpíadas no contexto escolar, isso porque são provocantes, mostram elementos e conceitos que incentivam os alunos a trabalharem ideias e argumentações sobre eles, com liberdade para estudar cada um no seu tempo e de sua maneira. De acordo com Pacheco e Pacheco (2013, p. 71), traz um cenário tradicional para "os objetivos da unidade escolar, além de aprender-ensinar para o cotidiano, é que se ensine- 
aprenda sobre o mundo em que vivemos e a respeito desse maior mistério que é o indivíduo". Em diversas olimpíadas, são apresentados problemas que os alunos necessitam ter muita originalidade e imaginação para resolvê-los. Bagatini (2010, p. 10) declara que "diante das diversas tentativas de incentivar o estudo da Matemática, alguns se sobressaem, entre elas as Olimpíadas de Matemática realizadas em diversas escalas (mundial, nacional, regional, etc.)".

Com essas questões, Lara e Lopes (2013) afirmam que são diversas as classificações em relação aos exemplos de problemas, mas autônomo do tipo utilizado em sala de aula, a resolução de situações-problema deve oportunizar aos estudantes o pensamento crítico e a análise, proporcionando o enfrentamento e a conquista nas decisões em diferentes situações. Além disso, as olimpíadas, à medida que acontecem, promovem uma grande participação de professores bem capacitados nessa área, desenvolvendo um aprendizado relevante para toda a comunidade escolar.

Diante disso, este artigo tem como o objetivo de: realizar uma Engenharia Didática pretendendo a estruturação de uma Situação Didática Olímpica (SDO), com ênfase no ensino de Geometria Plana e com o apoio do software educacional GeoGebra como recurso tecnológico, com o propósito de proporcionar a compreensão de novas resoluções aos alunos por meio dos comandos e visualizações das figuras expostas na situação-problema didática olímpica.

$\mathrm{Na}$ descrição da SDO, de modo simplificado, Alves relata sobre “[...] busca agregar uma perspectiva de transposição didática para os Problemas Olímpicos (PO), com interesse de proporcionar a discussão de elementos que precisam ser efetivamente incorporados na prática do professor de matemática" (ALVES, 2020, p. 321). Nesta perspectiva, o autor visa uma abordagem em relação a utilização destas questões em sala de aula que proporcione a participação e cooperação de todos os estudantes, e não apenas alunos competidores de olimpíadas de matemática.

Diante disso, a Canguru de Matemática Brasil junto a OBMEP, trabalha seus problemas com o público geral. A competição da IMO, tem critérios de seleção para participantes diferentes, conta com até seis estudantes e seu público-alvo é restrito, comparado às outras olimpíadas de Matemática. Além disso, possui outra proposta de questões abertas e discursivas, que muitas vezes passam por assuntos elementares não direcionados para público geral. O mesmo acontece na olimpíada da Cone Sul e Ibero-Americana, no qual os integrantes representando o Brasil, são os estudantes que se destacam nas etapas da OBM, sendo selecionado no processo final de cada olimpíada um número significativo de pessoas, entre 4 (quatro) a 6 (seis) integrantes, além de outros critérios seletivos.

No próximo tópico, serão apresentados os elementos sobre a metodologia de pesquisa da Engenharia Didática (ED) em suas fases iniciais (análise preliminar e $a$ priori) e com o suporte da Teoria das Situações Didáticas (TSD) "ação, formulação, validação e institucionalização" relacionado a esta investigação. 
A relevância dos problemas propostos em olimpíadas e seu tratamento didático no ensino de matemática é totalmente reconhecida pela comunidade acadêmica/científica, entretanto, na prática escolar existem preparatórios de matemática como por exemplo, aulas de olimpíadas de matemática, clubes de matemática e eletivas de matemática para elevar o nível de conhecimento do aluno a resolver problemas.

\section{Metodologia}

A pesquisa realizada no presente artigo, segue alicerçada no modelo metodológico da Engenharia Didática em consonância com as Situações Didáticas Olímpicas. Essa metodologia de pesquisa trabalhada por Artigue (1988), é compreendida em quatro fases, a saber: i) análise prévias, ii) concepção e análise a priori, iii) experimentação e iv) análise a posteriori e validação. Todavia, neste trabalho é apresentado somente as duas primeiras fases da ED, buscando uma análise bibliográfica de assuntos relevantes a olimpíadas de matemática, visando uma estruturação de uma SDO, metodologia de ensino baseada na Teoria das Situações Didáticas de Brousseau (1986), desenvolvida de forma pioneira por Alves (2016).

No começo do século XIX, havia certa preocupação ao que se refere a formação do professor de matemática e o processo de ensino adotado por ele. Nessa perspectiva, a partir dos anos 80 , começaram a ser fundados na França centros universitários objetivando a melhoria no sistema de ensino, nascendo a Engenharia Didática.

Conforme Artigue (1988), o vocábulo Engenharia Didática é proveniente da semelhança do trabalho didático desempenhado pelo docente ao de um engenheiro, ao qual, para execução de um projeto, o profissional baseia-se em seus conhecimentos científicos, aceitando se submeter a um controle científico, contudo, ao mesmo tempo é submetido a trabalhar objetos mais complexos do que os objetos de cunho científico.

A Engenharia Didática, de acordo com Douady (1995), trata-se de uma metodologia de pesquisa composta por uma sequência de classes concebidas, organizadas e articuladas no tempo, de forma coerente por um professor-engenheiro, com o objetivo de investigar um projeto de aprendizagem voltada para um determinado grupo de estudantes. Desse modo, o docente assume a posição de um engenheiro, onde cria um planejamento embasado nos interesses de ensino dos alunos.

Conforme os pressupostos de Artigue (1988) a Engenharia Didática é composta por quatro fases. Na primeira fase, intitulada análise prévia ou preliminar, é realizado uma investigação sobre os obstáculos/dificuldades do ensino e aprendizagem de matemática. Nessa fase também são formulados os questionamentos, hipóteses e os aspectos teóricos metodológicos da pesquisa (LIMA, 2019). 
Já na segunda fase, classificada como concepção e análise a priori, elabora-se um conjunto de situações didáticas onde, segundo Almouloud (2007, p.174) “devem ser concebidas de modo a permitir ao aluno agir, se expressar, refletir e evoluir por iniciativa própria, adquirindo assim novos conhecimentos". O professor, por sua vez, planeja a aula prevendo os acontecimentos e aponta passoa-passo a serem realizados durante a aplicação.

Na experimentação, ou terceira fase, coloca-se em prática o que foi planejado na fase anterior, ou seja, é a aplicação da Situação Didática (SD). Na quarta e última fase, denominada análise $a$ posteriori e validação, é realizado um estudo dos resultados obtidos pelo professor-pesquisador, por meio de instrumentos investigativos como anotações, vídeos e questionários. Por fim, é feito um confronto entre os dados coletados na análise a priori com os dados coletados a posteriori.

A concepção de SDO está associada a SD, que provém da Teoria das Situações Didáticas, assim, Alves (2021) descreve a SDO como um grupo de relações estabelecidas implícita ou explicitamente, guiado pela metodologia de ensino TSD entre um estudante ou grupos de estudantes, um certo meio (saber) e um sistema educativo para olimpíadas. Santos e Alves (2017, p. 451) definem SD como "um conjunto de situações reprodutíveis que permitem a organização do espaço de sala de aula e dos momentos de interação entre o professor, o aluno e o saber, no meio organizado". O professor, por sua vez, deve manter-se atento as condições de exposição de certos conteúdos matemáticos, deixando claro para os estudantes a sua intenção em possibilitar a aprendizagem.

Com o intuito de investigar as relações que existem entre as atividades de ensino com as possibilidades de uso do saber matemático, a SDO é organizada em quatro etapas da TSD: situação de ação, de formulação, de validação e de institucionalização descritos na Tabela 1. Durante esse processo, os estudantes comunicam-se entre si e com o meio, em busca de soluções pertinentes, e o docente assume o papel de mediador. Santos e Alves (2017, p. 451) descrevem características importante sobre cada uma dessas fases:

Tabela 1 - Descrição das etapas da TSD.

\begin{tabular}{|c|l|}
\hline Etapas & \multicolumn{1}{|c|}{ Descrições } \\
\hline Situação da Ação & $\begin{array}{l}\text { Nesta etapa, cabe ao aluno, de posse do problema, buscar em } \\
\text { seus conhecimentos, interagindo com o meio, elementos } \\
\text { necessários à solução da situação proposta que se processa por } \\
\text { meio de reflexões e tentativas, a fim da obtenção de uma } \\
\text { estratégia de resolução. }\end{array}$ \\
\hline Situação de Formulação & $\begin{array}{l}\text { Caracterizada pela troca de informações entre o aluno e o meio } \\
\text { organizado. Neste momento, já se permite a utilização de uma } \\
\text { linguagem adequada, mas sem formalidade obrigatória, ou seja, } \\
\text { existe uma organização de informações para torná-las } \\
\text { comunicáveis. }\end{array}$ \\
\hline Situação de Validação & $\begin{array}{l}\text { Fase de convencimento dos interlocutores sobre a veracidade, ou } \\
\text { não, dos argumentos apresentados à solução do problema. Neste }\end{array}$ \\
\hline
\end{tabular}


ponto, já se deve utilizar uma linguagem mais formalizada e mecanismos de prova.

Situação de Institucionalização

Etapa em que a intenção do professor, tendo com meio o problema proposto, é revelada.

Fonte: Santos e Alves (2017), adaptado.

Sobre a Situação Didática Olímpica, Lima (2019) acentua que esta é uma associação da Teoria das Situações Didáticas, como metodologia de ensino a problemas olímpicos (situações problemas de matemática no contexto competitivo de ação individual para atingir as premiações), com o intuito de fornecer aos estudantes um ambiente de aprendizagem em que eles tenham autonomia para, com o mínimo de ajuda do docente, buscando solucionar tais problemas olímpicos.

De acordo com Alves (2020, p. 325), uma SDO é:

Um conjunto de relações estabelecidas implicitamente ou explicitamente, balizadas por uma metodologia de ensino (TSD), entre um aluno ou grupo (s) de alunos, um certo meio (compreendendo ainda o conhecimento matemático abordado por intermédio de problemas de competição e de olimpíadas) e um sistema educativo, com o objetivo de permitir a apropriação, por parte destes alunos um conhecimento constituído ou em vias de constituição, oriundo de um ambiente de competição coletiva e debate científico, competição solidária e problemas ou conjunto de problemas característicos e abordados nas olimpíadas de Matemática.

O autor ainda define uma equação que caracteriza uma Situação Didática Olímpica, a saber, $S D O=P O+T S D$, assim, PO trata-se de Problemas Olímpicos. Nessa perspectiva, apresenta-se na seção subsequente os resultados obtidos a partir da análise preliminar.

\section{Análises preliminares do Problema Olímpico}

$\mathrm{Na}$ análise preliminar, realiza-se um estudo bibliográfico de assuntos relacionados ao ensino e um contexto de olimpíadas internacionais de Matemática. Conforme Almouloud e Coutinho (2008, p.66), descreve as seguintes concepções:

(i) epistemológica dos conteúdos visados pelo ensino; (ii) do ensino usual e seus efeitos; (iii) das concepções dos alunos, das dificuldades e dos obstáculos que marcam sua evolução; (iv) das condições e fatores de que depende a construção didática efetiva; (v) a consideração dos objetivos específicos da pesquisa; (vi) o estudo da transposição didática do saber considerando o sistema educativo no qual insere-se o trabalho.

Almouloud (2004), embora a Geometria seja um conteúdo importante da Matemática, por exercer de ferramenta para diversas áreas do conhecimento, existem nos dias de hoje, problemas relacionados ao seu ensino, caracterizados pela falta de correlação com outras áreas do conhecimento, o que impede um olhar mais amplo e crítico por parte do aluno. Nesse processo, Cabariti (2006) cita algumas das pesquisas e práticas de ensino derivadas da revisão de informações, que evidenciam o 
interesse dos professores por uma proposta de ensino que possibilite o aprofundamento da geometria euclidiana, cujos conceitos são ministrados no ensino básico. A autora relata sobre a importância da Geometria, poder relacionar um estudo sobre o tópico da Geometria Esférica com auxílio de um aplicativo digital.

Nessa perspectiva é expressivo pesquisas de cunho acadêmico que visam a melhoria no ensino de problemas olímpicos. Ao realizar uma busca no repositório de teses e dissertações do Mestrado Profissional de Matemática em Rede Nacional (PROFMAT) no intercepto temporal de 2016 a 2020, verificou-se um expressivo número de 36 produções acadêmicas (Tabela 2) que versam sobre a preparação para as Olimpíadas de Matemática que discutam sobre metodologias direcionada para o professor trabalhar na resolução do PO, para que os alunos participem ativamente na construção do processo de ensino e aprendizagem dos conteúdos trabalhados.

Tabela 2 - Títulos acadêmicos com as dissertações pesquisadas no repositório do PROFMAT.

\begin{tabular}{|c|c|c|c|}
\hline $\begin{array}{c}\text { Total de } \\
\text { Dissertações }\end{array}$ & $\begin{array}{c}\text { Olimpíada de Matemática } \\
(\mathbf{2 0 1 6} \text { a 2020) }\end{array}$ & Percentual & Data da Pesquisa \\
\hline 5643 & 36 & $0,64 \%$ & 03 a $11 / 03 / 2020$ \\
\hline
\end{tabular}

Fonte: Elaborado pelos autores, a partir do site do PROFMAT (2020).

Portanto, pode-se tirar a conclusão da tabela acima, que a participação quantitativa e percentual de trabalhos sobre o tema "Olimpíadas da Matemática", comparando-o com outros temas da pesquisa matemática ao longo de vários anos, o que é lamentável, pois o programa PROFMAT tem uma ampla cobertura em todo o Brasil, sendo relevante abordar as questões relacionadas à prática em sala de aula do professor da educação básica no âmbito do citado tema, neste contexto da IMO.

Em seu estudo, Badaró (2015), elabora um material para auxiliar os docentes na preparação dos estudantes voltados para a OBM, fazendo sugestões de aulas pautada na resolução de problemas. Já Fideles (2014) seleciona alguns problemas do Banco de Questões da OBMEP e outras olímpiadas, e aponta a resolução desses problemas por meio do método de Resolução de Problemas de Pólya, objetivando "explorar a resolução para ajudar o aluno a desenvolver a habilidade de resolver problemas com confiança e autonomia e construir o conhecimento matemático" (FIDELES, 2014, p. 24). A autora ainda trata da abordagem desses problemas para as turmas do $2^{\circ}$ ano do Ensino Médio e a importância de utilizar ferramentas tecnológicas criando um ambiente de discussão online ampliando a troca de experiências.

Nas produções encontradas no repositório da Universidade Federal do Ceará (UFC), destacam-se a de Oliveira (2016) e Lima (2019). Intitulada “Olimpíadas de Matemática: concepção e Descrição de 'Situações Olímpicas' com o recurso do software GeoGebra”, Oliveira (2016) 
descreve situações didáticas utilizando como metodologia de ensino a Teoria das Situações Didática para a resolução de problemas olímpicos de nível 3 da OBMEP (Olimpíada Brasileira de Matemática das Escolas Públicas). Em sua pesquisa o autor propõe a reflexão de problemas de Geometria Plana com o aporte do software de geometria dinâmica o GeoGebra. Ressalta-se que o autor foi o primeiro a usar o termo "Situação Didática Olímpica" a nível de dissertação.

Em sua pesquisa, Lima (2019) também apresenta propostas de ensino voltadas para a preparação olímpicas, especificamente a OBMEP, utilizando as Situações Didáticas Olímpicas sob a luz da TSD como metodologia de ensino de Sequência Numéricas. A autora elabora dez Situações Didáticas Olímpicas voltados para o ensino do referido conteúdo.

De posse dos resultados dessa análise, nota-se uma carência no número de pesquisas direcionadas para metodologias de ensino inseridas no cenário das olimpíadas de Matemática. A maior parte das pesquisas encontras são voltadas para a resolução de problemas olímpicos, mas não deixa claro a metodologia de ensino utilizada pelo professor, e nenhuma delas refere-se as Olímpiadas Internacionais de Matemática. De acordo com Alves (2021, p. 125) afirma que:

\footnotetext{
Problema Olímpico (PO): um conjunto de situações problemas de Matemática, abordado em um contexto competitivo ou de maratonas, com a participação apenas (e de modo restritivo) dos estudantes competidores, cuja abordagem e características de ação individual e solitária destes envolve apenas objetivo/escopo de se atingir as metas (medalhas e certificados) definidas a priori em cada competição por intermédio do emprego de estratégias especializadas, raciocínios e argumentos matemáticos eficientes, instrumentalizados previamente por professores de Matemática.
}

O autor apresenta a importância do PO na resolução de questões olímpicas, estruturadas de forma diversa, aplicando o nível de acordo com a situação-problema da IMO. Ainda considerando os resultados obtidos, destaca-se a importância na reformulação das propostas pedagógicas das aulas de Matemática, conforme a competência geral/específica da Base Nacional Comum Curricular (BNCC) os alunos devem "mobilizar seu modo próprio de raciocinar, representar, comunicar, argumentar e, com base em discussões e validações conjuntas, aprender conceitos e desenvolver representações e procedimentos cada vez mais sofisticados" (BRASIL, 2018, p. 529). Ou seja, o aluno deve ser protagonista seja na preparação para as olimpíadas seja nas aulas de Matemática.

\section{Concepção e análise a priori do Problema Olímpico}

Essa etapa é de fundamental importância para o trabalho. A partir das análises prévias realizadas durante a pesquisa, o pesquisador emprega a decisão de trabalhar sobre os valores numéricos que permite serem importantes a situação-problema da pesquisa e também sobre as 
variáveis que podem direcionar a caminhos ou soluções para o problema olímpico, Artigue (1996), descreve que:

\begin{abstract}
A primeira fase na qual se realizam as análises preliminares, que pode comportar as seguintes vertentes: (a) Epistemológica dos conteúdos visados pelo ensino; (b) $\mathrm{O}$ ensino usual e seus efeitos; (c) As concepções dos alunos, das dificuldades e dos obstáculos que marcam sua evolução; (d) As condições e fatores de que depende a construção didática efetiva; (e) A consideração dos objetivos específicos da pesquisa; (f) $\mathrm{O}$ estudo da transposição didática do saber considerando o sistema educativo no qual insere-se o trabalho. (ARTIGUE, 1996, p. 198).
\end{abstract}

Para Artigue (2014) as escolhas determinam as variáveis didáticas separadas em duas situações: "[...] macro e micro-didática variáveis" (p. 472). Através das escolhas as "variáveis condicionam o meio, portanto, as interações entre os alunos e conhecimento, as interações entre alunos e entre alunos e professores, assim, as oportunidades exatas que os alunos têm de aprender, como e o que eles podem aprender" (ARTIGUE, 2014, p. 472).

Portanto, observa-se a necessidade da utilização do software educacional GeoGebra, como recurso didático nas aulas preparatórias de olimpíadas de matemática, proporcionando ao estudante a assimilação de novas estratégias referentes a Situação Didática Olímpica (SDO), por meio da modelagem das situações-problema e a visualização da figura no aplicativo.

\title{
4.1 Proposta didática olímpica internacional
}

O problema apresentado foi extraído da avaliação da Olimpíada Internacional de Matemática (IMO), realizada em 2012 para estudantes do Ensino Médio (Pré-universitários) referente ao conteúdo de geometria plana. Essa questão deve apresentar os seguintes conceitos como: Teorema bissetriz interna (Teorema de Pitágoras), Teorema bissetriz externa (Teorema de Tales), Perpendicularidade, Quadriláteros inscritíveis, dando destaque a figura do triângulo retângulo unida a circunferência exinscrita.

Problema 1: (Problema da IMO 2012 - Geometria - $1^{\circ}$ Dia - Questão 01) Dado um triângulo $A B C$, o ponto $J$ é o centro da circunferência ex-inscrita oposta ao vértice $A$. Esta circunferência ex-inscrita é tangente ao lado $B C$ em $M$, e às retas $A B$ e $A C$ em $K$ e $L$, respectivamente. As retas $L M$ e $B J$ intersectam-se em $F$, e as retas $K M$ e $C J$ intersectam-se em $G$. Seja $S$ o ponto de interseção das retas $A F$ e $B C$, e seja $T$ o ponto de interseção das retas $A G$ e $B C$.

Prove que $M$ é o ponto médio de $S T$.

(A circunferência ex-inscrita de $A B C$ oposta ao vértice A é a circunferência tangente ao segmento $B C$, ao prolongamento do segmento $A B$ no sentido de $A$ para $B$ e ao prolongamento do segmento $A C$ no sentido de $A$ para $C$ ). 
Na Figura 1, apresenta-se a questão 01 extraída da prova da IMO (2012) em português, tem que a solução produzida pelo entendimento do aluno ao buscar subjetividade relacionando a noção de figuras geométricas planas, presente na estruturação do texto.

Figura 1 - Problema IMO 2012 (Língua - Português).

Problema 1. Dado um triângulo $A B C$, o ponto $J$ é o centro da circunferência ex-inscrita oposta
ao vértice $A$. Esta circunferência ex-inscrita é tangente ao lado $B C$ em $M$, è às retas $A B$ e $A C$ em $K$
e $L$, respectivamente. As retas $L M$ e $B J$ intersectam-se em $F$, e as retas $K M$ e $C J$ intersectam-se
em $G$. Seja $S$ o ponto de interseçāo das retas $A F$ e $B C$, e seja $T$ o ponto de interseçāo das retas $A G$
e $B C$.
Prove que $M$ é o ponto médio de $S T$.
(A circunferência ex-inscrita de $A B C$ oposta ao vértice $A$ é a circunferência tangente ao segmento
$B C$, ao prolongamento do segmento $A B$ no sentido de $A$ para $B$ e ao prolongamento do segmento
$A C$ no sentido de $A$ para $C$.)

Fonte: IMO (2020), Disponível em: http://www.imo-official.org/problems.aspx.

A IMO 2012 foi realizada na cidade Mar Del Prata, Argentina. Problema proposto pela delegação da Grécia.

Dessa forma, o PO elaborado sob a perspectiva da TSD de Guy Brousseau (1986) em suas quatro etapas (ação, formulação, validação e institucionalização). A SDO construída tem o suporte tecnológico educacional do software GeoGebra, a presente figura organizada no problema olímpico foi ajustada (Figura 2) a esse programa computacional/aplicativo permitindo a deslocação e visualização da modelagem dos elementos, dando mais incentivos aos alunos durante a resolução.

Figura 2 - Desenvolvimento no GeoGebra da SDO 01 (Parte 1).

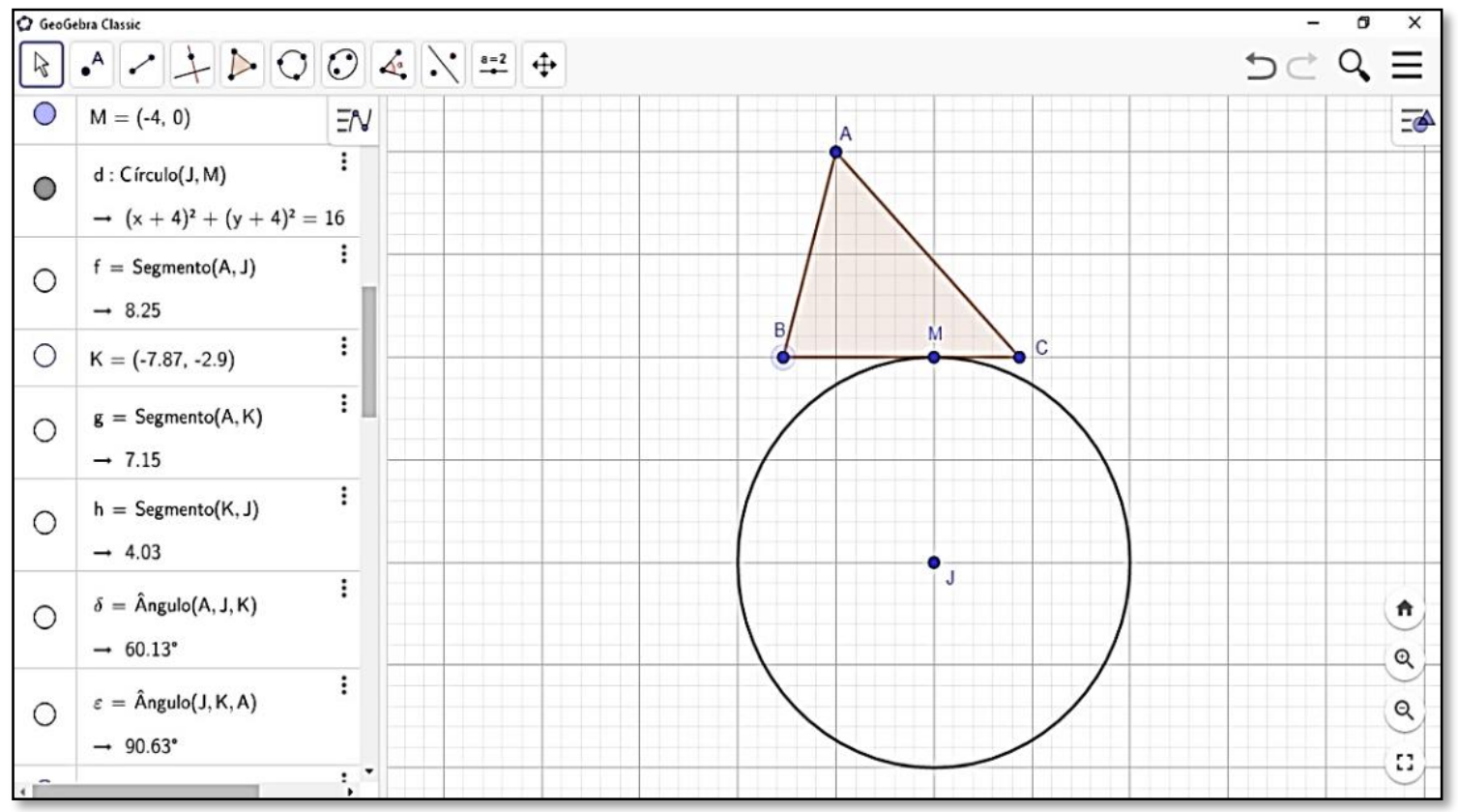

Fonte: Elaborado pelos autores (disponível em: https://www.geogebra.org/m/fhupbmsu). 
Na etapa de ação, segundo Almouloud (2007, p. 36-40), “essa etapa coloca um problema proposto para o aluno cuja melhor resolução, nas condições direcionadas, é o conhecimento a ensinar; o aluno possa realizar sobre essa situação-problema e que ela lhe retorne informações sobre sua ação".

Dessa maneira, o estudante analisando a questão olímpica, deve perceber algumas informações que o leve para o melhor método a ser aplicado. É necessário que eles examinem os pontos $B K=B M$ entre os pontos $B K$ e $B M$ são ambos tangentes do $B$ círculo $J$ conforme (Figura 3). Então $B J$ e $K M$. Seja $X$ a intersecção entre $B J$ e $K M$. Da mesma maneira, deixe a entre os segmentos da reta perpendicular $C J$ e $L M$ ser $Y$. Descrevendo que $\angle X B M=\angle X B K=\angle F B A$ e $\angle X M B=\angle X K B$. O docente deve incentivar os estudantes a examinarem a partir dos comandos para a estruturação do triângulo retângulo unida na circunferência construída no software GeoGebra que ajudarão para a sequência da resolução da questão.

Na próxima etapa as deslocações realizadas no programa educacional GeoGebra, por meio dos comandos, o aluno chegará a seguinte sequência na (Figura 3) e (Figura 4).

Figura 3 - Desenvolvimento no GeoGebra da SDO 01 (Parte 2).

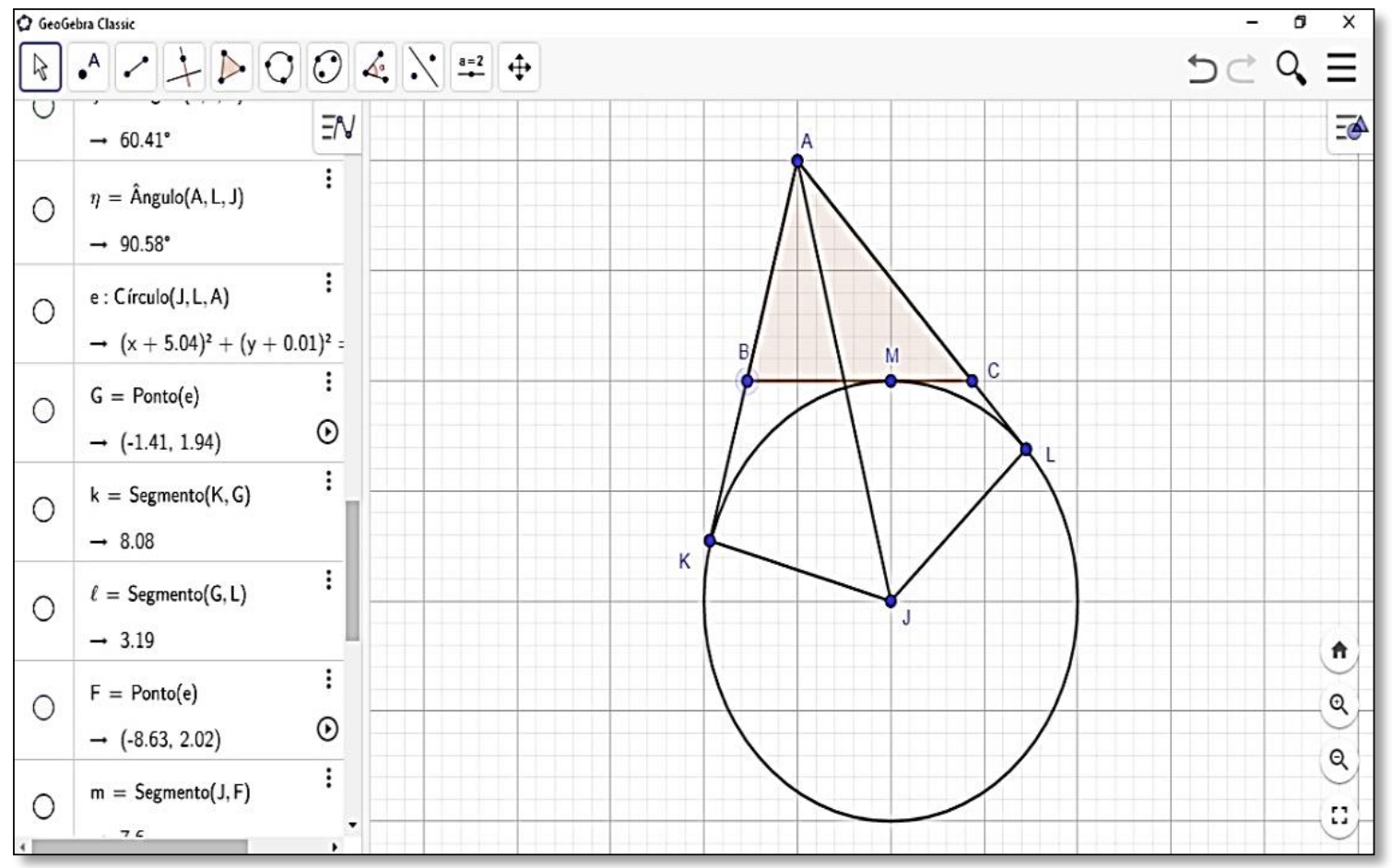

Fonte: Elaborado pelos autores.

Nesta fase acontece as argumentações, a comparação dos princípios e suposições com o que foi mencionado ou relato entre os estudantes sobre o procedimento de resposta na questão. Segundo Almouloud (2007, p. 36-40), “o aluno troca informações com uma ou várias pessoas do grupo, que serão os emissores e receptores, trocando mensagens escritas ou orais entre si”. Se necessário, o 
professor pesquisador poderá até esse momento conduzir os estudantes a realizar indagações relacionando o conceito de exposição da prática didática.

Neste processo, a descrição acontece que $\angle X B M+\angle X B K+\angle X M B+\angle X K B=\angle M B K+$ $\angle X M B+\angle X K B=\angle M B K+\angle K M B+\angle M K B=180^{\circ}$. Então $\angle X B M=90^{\circ}-\angle X M B$. Relevante no ângulo de $180^{\circ}=\angle F B A+\angle A B C+\angle X B M=2 \angle X B M+\angle A B C=180^{\circ}-2 \angle X M B+\angle A B C$. Então $\angle A B C=2 \angle X M B$. Observando agora que $\angle X F M=90^{\circ}-\angle X M B-\angle B M F=90^{\circ}-\angle X M B-\angle Y M C$. Seguindo $\angle A C B=2 \angle Y M C$. $\angle B A C=180^{\circ}-\angle A B C-\angle A C B=180^{\circ}-2(\angle X M B+Y M C)=2\left(90^{\circ}-\right.$ $(\angle X M B+\angle Y M C)=2 \angle X F M)$. Da mesma Forma $\angle B A C=2 \angle Y G M$.

Figura 4 - Desenvolvimento no GeoGebra da SDO 01 (Parte 3).

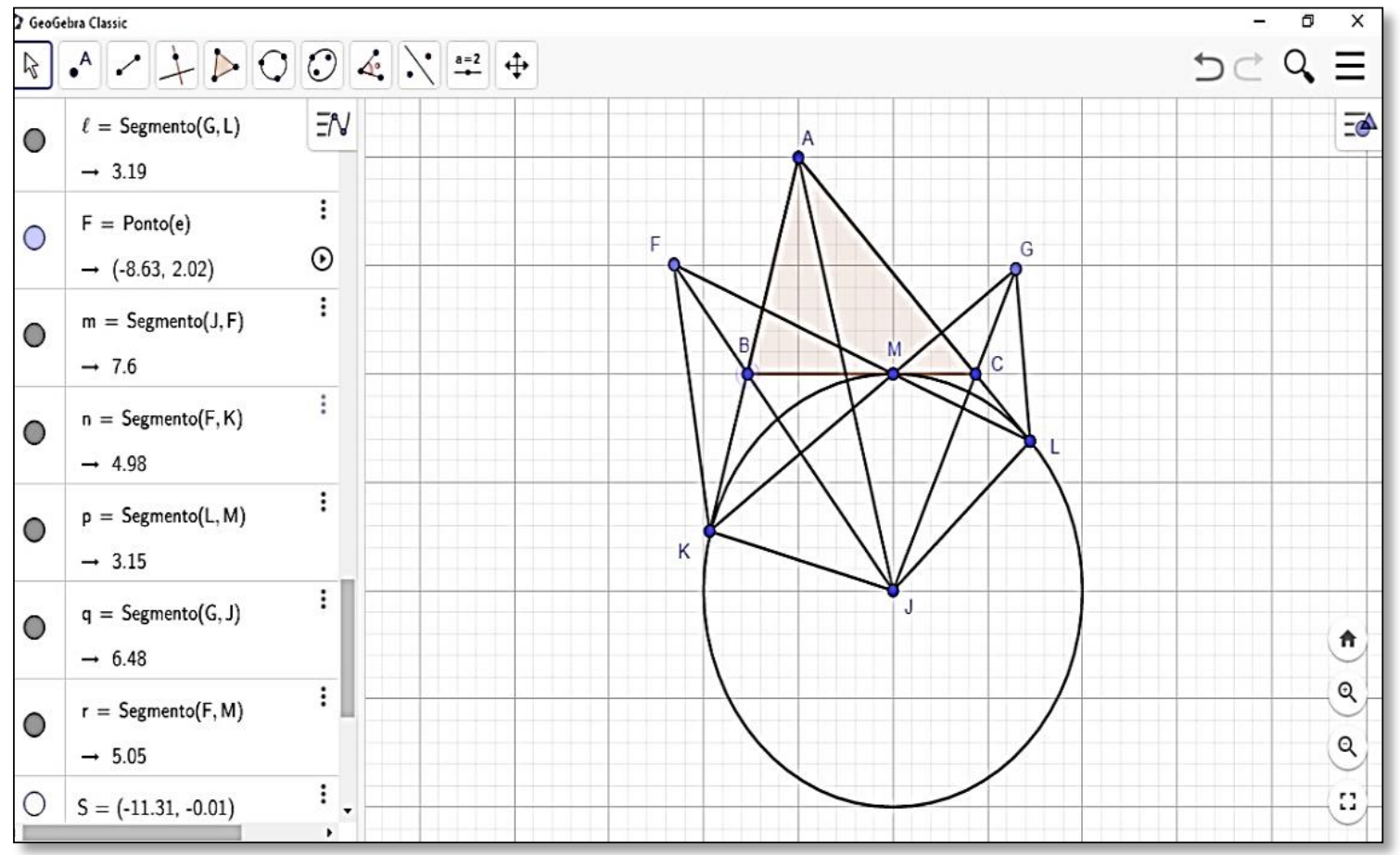

Fonte: Elaborado pelos autores.

Dessa maneira, dando continuidade à resolução é aguardado que edifiquem a partir do reconhecimento dos segmentos de linha $F K$ e $G L . \triangle F X K$ e $\triangle F X M$ são congruentes $\triangle G Y L$ e $\Delta G Y M$ são congruentes da quadrilateral $A F J L$ é cíclico porque $\angle J A L=\angle B A C / 2=\angle X F M=\angle J F L . \mathrm{O}$ quadrilátero $A F K J$ também é cíclico porque $\angle J A K=\angle B A C / 2=\angle X F M=\angle X F X=\angle J F K$. O circuncírculo de $\triangle A F J$ também contém os pontos $K$ e $J$ porque há um círculo ao redor dos quadriláteros $A F J L$ e $A F K J$. Portanto, o pentágono $A F K J L$ também é cíclico (Figura 6).

Portanto, seja de interesse do leitor, a figura a seguir disponibiliza o $Q R$ Code de acesso da construção da SDO 01 (Parte 04) no GeoGebra: 
eISSN: 2526-9062

Figura 5 - QR Code para acesso da construção da Situação Didática Olímpica 01 no GeoGebra.

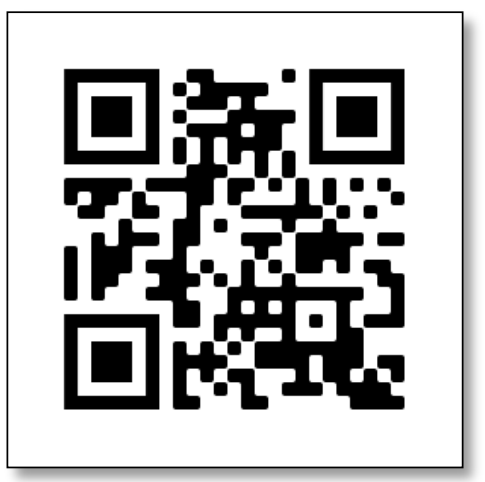

Fonte: Elaborado pelos autores.

Nesta etapa, deseja-se que exista uma conversa sobre a Situação Didática Olímpica (SDO), validação dos princípios no decorrer de sua resolução e, segundo Almouloud (2007, p. 36-40), “essa etapa na qual o estudante deve mostrar a validade do modelo por ele estruturado, submetendo a comunicação matemática ao julgamento de um interlocutor”. Ademais, é desejado que os alunos utilizem de suporte ao software GeoGebra para os demais colegas tentarem comparar e buscar o padrão de resolução da SDO.

Figura 6 - Desenvolvimento no GeoGebra da SDO 01 (Parte 04).

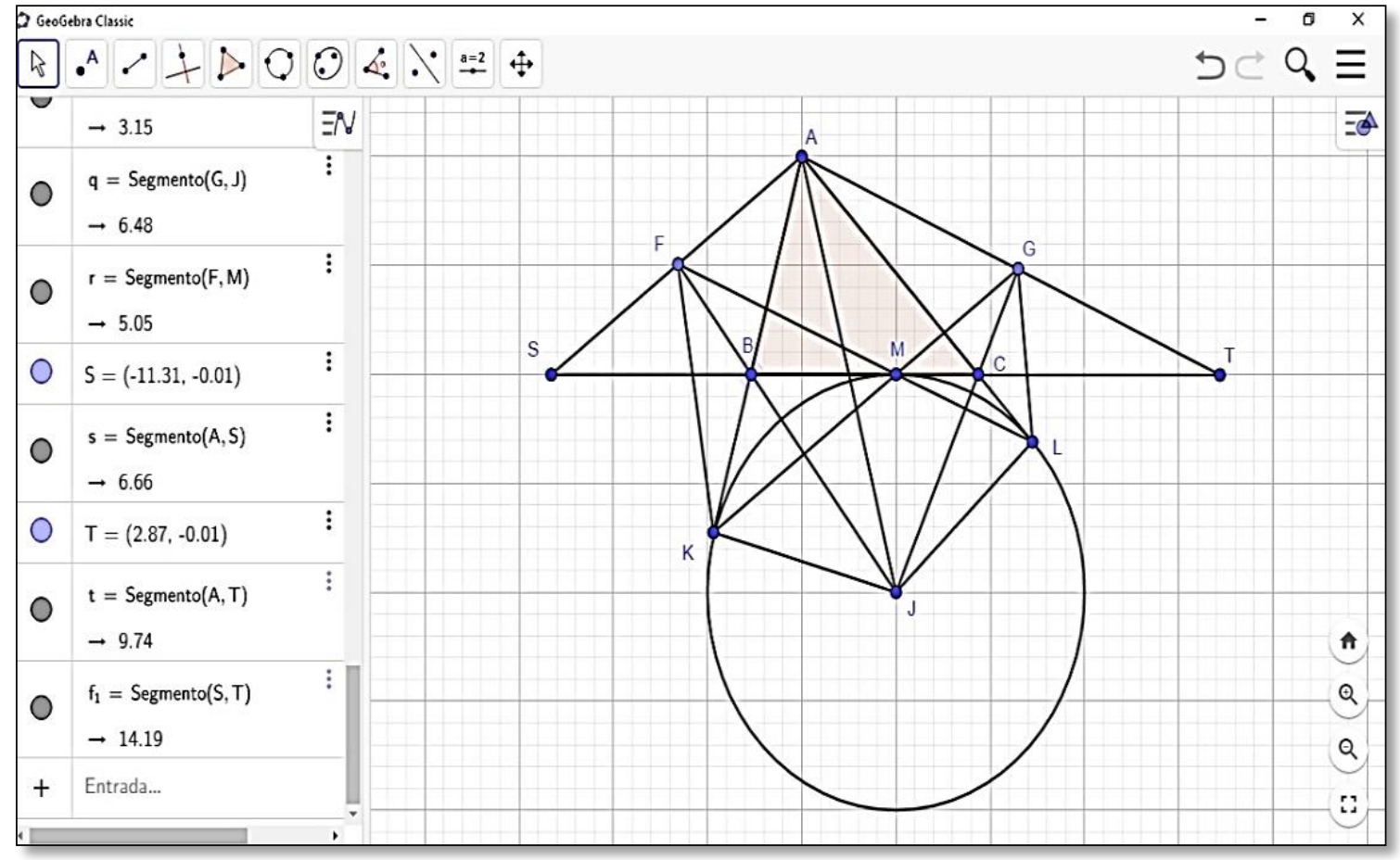

Fonte: Elaborado pelos autores.

De outra forma, espera-se ainda que o GeoGebra possibilite a construção de saberes matemáticos compreendido no ensino tradicional de questão, pretendendo auxiliar na alegação no resultado dela descrito na Figura 7. 
Figura 7 - Desenvolvimento no GeoGebra da SDO 01 (Parte 5).

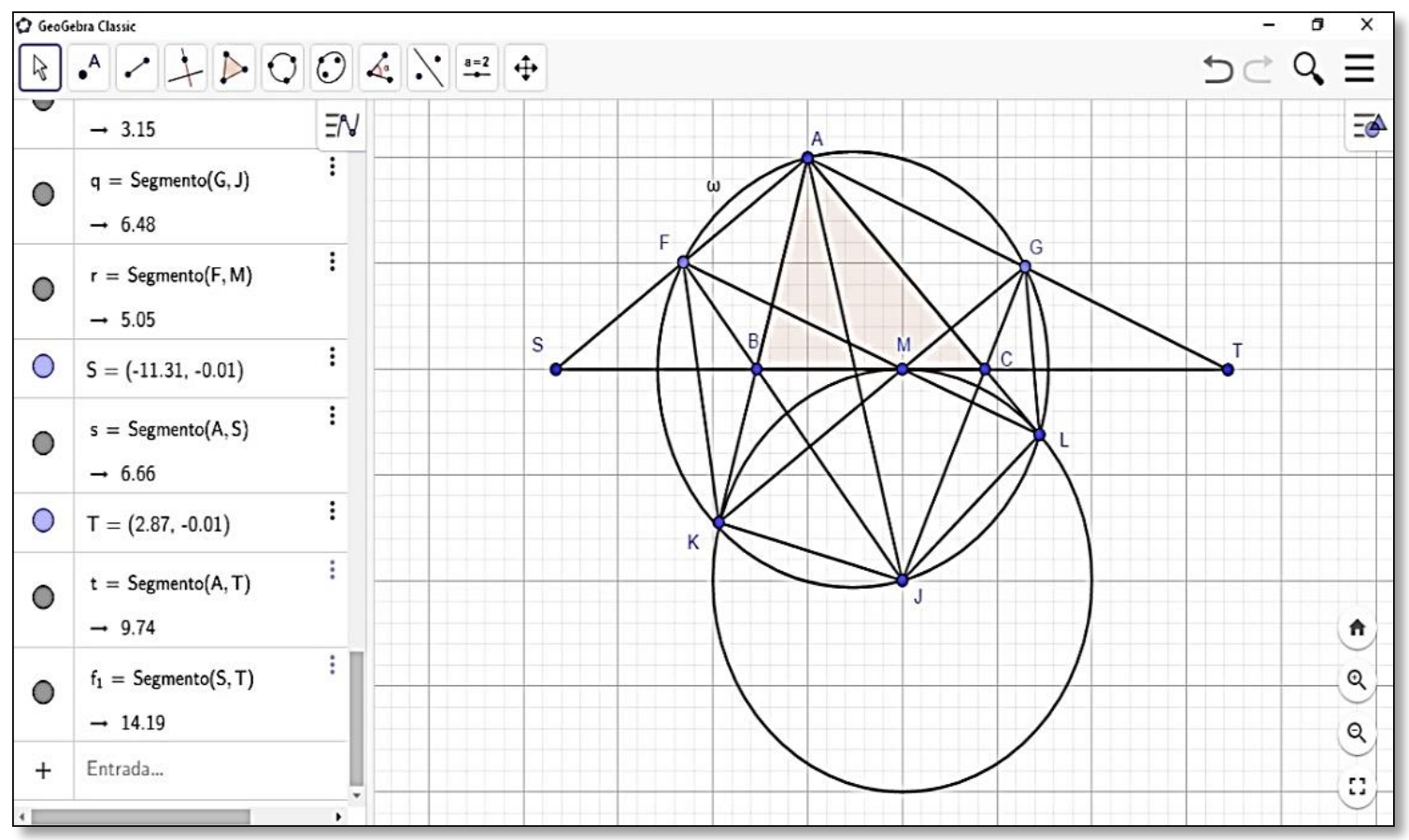

Fonte: Elaborado pelos autores.

Na Figura 8 mostra-se a construção do quadrilátero $A G L J$ é cíclico porque $\angle J A L=\angle B A C / 2$ $=\angle Y G M=\angle Y G L=\angle J G L$. Entretanto, $\triangle A J L$ é comum em ambos o pentágono cíclico $A F K J L \mathrm{e}$ quadrilátero cíclico $A G L J$, de modo que a circunferência circunscrita $\triangle A J L$ também contém os pontos $F, K$ e $G$., portanto o hexágono $A F K J L G$ é cíclico. Uma vez que $\angle A K J$ e $\angle A L J$ são ambos ângulos retos, $A J$ é o diâmetro do círculo em torno do hexágono cíclico $A F K J L G$. Seguindo, $\angle A F J$ e $\angle A G J$ são ambos ângulos retos. $\triangle B F S$ e $\triangle B F A$ são congruentes pela congruência, e assim são $\triangle C G T$ e $\triangle C G A$. Tem-se $S B=A B \cdot T C=A C \cdot B M=B K$, e $C M=C L$. Desde que $A K$ e $A L$ são tangentes de $A$ ao círculo $J, A K=A L$. Então, o processo chega no desenvolvimento de $A K=A L$, o que se torna $A B+$ $B K=A C+C L$, sendo $S B+B M=T C+C M$ ou $S M=T M$. Isso significa que $M$ é o ponto médio de $S T$. 
Figura 8 - Desenvolvimento no GeoGebra da SDO 01 (Parte 6).

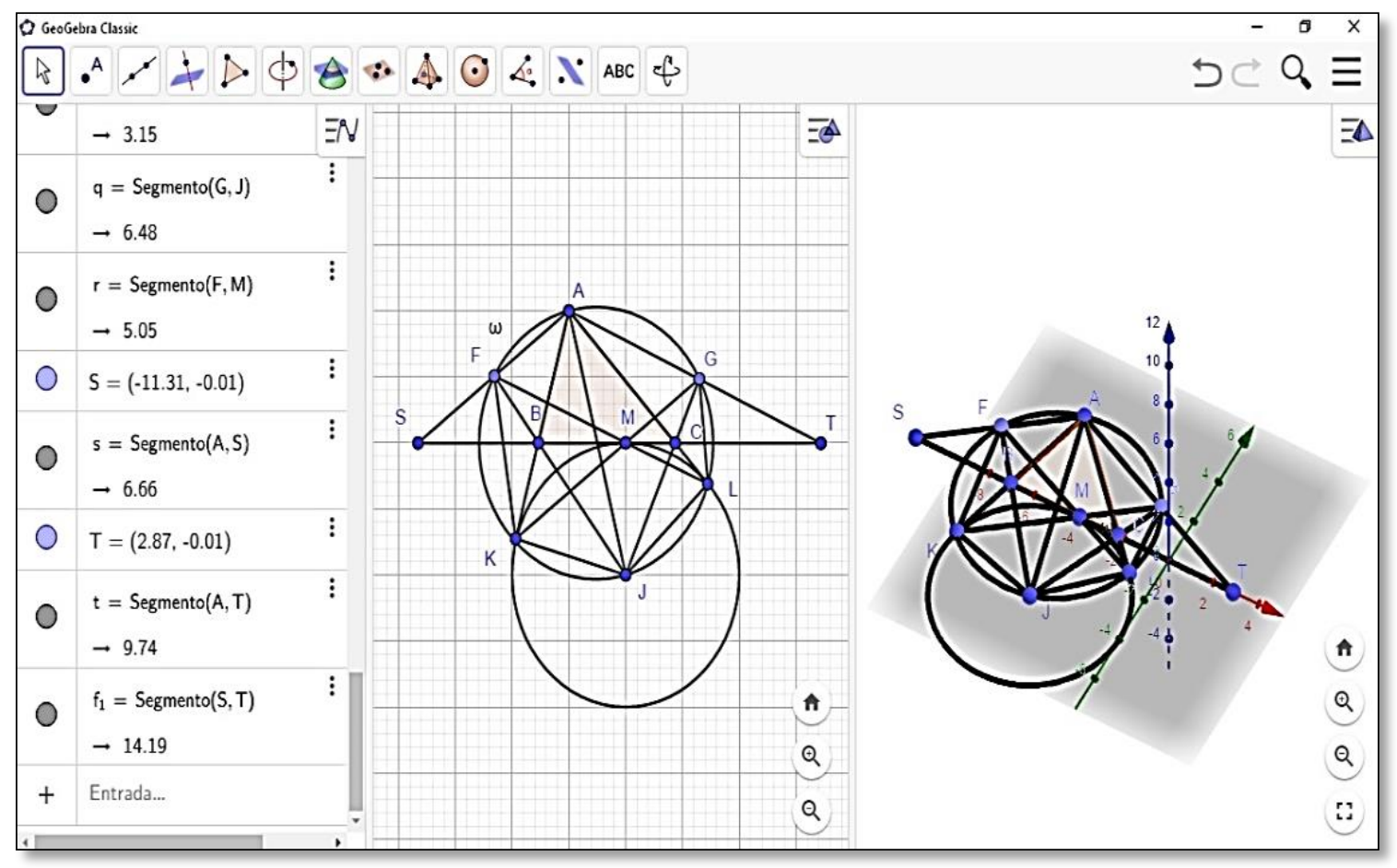

Fonte: Elaborado pelos autores.

Na etapa de institucionalização, segundo Almouloud (2007, p. 36-40) descreve "o professor fixa propositadamente e explicitamente o processo cognitivo do saber". Desta forma, o docente tem um contexto de caráter didático, notado que além de ter uma função ativa, ocorre um diálogo dele, do aluno e do saber diante da situação problema caso o aluno não consiga ter êxito na resposta.

A Situação Didática Olímpica desenvolvida procurou por meio da modelagem e visualização da figura encontrar outros caminhos para resposta da questão, o que será capaz de ser uma diferença para o professor de Matemática dentro da sala de aula para atrair atenção dos alunos e, também conseguirá um número maior de participações de estudantes olímpicos e não olímpicos.

\section{Considerações finais}

A presente pesquisa teve como proposta de trabalho abordar uma Engenharia Didática (ED) em duas etapas iniciais (Análises preliminares e a priori) visando a estruturação de uma Situação Didática Olímpica (SDO) para o ensino de matemática relativo a geometria plana, com destaque na modelagem do triângulo retângulo inscrito em uma circunferência, por intervenção de uma questão da Olimpíada Internacional de Matemática (IMO), unido a aplicação do software educacional GeoGebra como instrumento que possibilite o aluno através do processo da modelação e visualização de novos métodos no instante da sua resposta. 
Em relação a Engenharia Didática (ED), ressaltou-se a sua importância na elaboração da situação didática, realizando um estudo prévio para o professor pesquisador de matemática identificar problemas comuns sobre o ensino de geometria, dando estrutura para contribuir com a diminuição e superação dos obstáculos expostos ao longo do processo de modelagem junto ao software GeoGebra para a resolução da SDO.

A Teoria das Situações Didáticas (TSD), apresenta-se eficaz para o professor pesquisador de matemática na compreensão dos conceitos estudados em sala de aula, desempenhando moderadamente, a progressão de todas as fases para interação com o meio (milieu), representado pelo problema olímpico matemático proposto junto ao software educacional GeoGebra embasado no entendimento adquirido por procedimento da Engenharia Didática (ED), que favorecerá o estudante a distinção do saber de ação, formulação e validação das métodos e das respostas mostradas, e que lhe garanta uma maior liberdade, o que poderá destacar a prática e participação em sala de aula.

A Situação Didática Olímpica (SDO) procurou envolver conhecimentos na modelagem de conceitos geométricos da geometria plana em relação a sequência didática olímpica, unida aos conjuntos de soluções disponibilizados pelo docente e com apoio no manuseio do recurso tecnológico do software GeoGebra para os comandos e visualização, o que atrairá atenção por partes dos alunos.

Portanto, se fazem necessárias ulteriores pesquisas, relativo ao tema aqui investigado, e que venham a ajudar aos professores que pretendem ensinar os conceitos matemáticos de geometria plana por meio deste modelo didático de ensino mostrado neste trabalho, usando questões da IMO. A referida pesquisa faz parte de um estudo em andamento que integrará a dissertação de mestrado profissional na área do Ensino de Matemática aplicado as Tecnologias Educacionais deste autor, onde o mesmo oferece no ensino de matemática o uso de problemas olímpicos auxiliado pelo software GeoGebra na estruturação de situações didáticas de ensino em Geometria Plana para educação básica.

\section{Referências}

ALMOULOUD, S. A. A geometria no ensino fundamental: reflexões sobre uma experiência de formação envolvendo professores e alunos. Revista Brasileira de Educação, São Paulo, n. 27, pp. 94 - 108, Set /Out/Nov/Dez 2004.

ALMOUlOUD, S. A. Fundamentos da Didática da Matemática. Editora UFPR. São Paulo: Brasil. 2007.

ALMOULOUD, S.; COUTINHO, C. Q. S. Engenharia Didática: características e seus usos em trabalhos apresentados no GT-19 / ANPEd. Revemat. v. 3. n. 6, pp. 62-77, UFSC: 2008. Disponível em: < https://periodicos.ufsc.br/index.php/revemat/article/view/1981-1322.2008v3n1p62/12137>. Acesso em 06 dez. 2020. 
ALVES, F. R. Engenharia Didática para a generalização da sequência de Fibonacci: uma experiência num curso de licenciatura. Educação Matemática Pesquisa, v. 18, n. 1, pp. 61-93, 2016.

ALVES, F. R. Engenharia Didática para o Ensino de Variável Complexa: Visualização de Conceitos Relacionados ao Processo Matemática de Integração. Alexandria-Revista de Educação em Ciência e Tecnologia, v. 11, n. 2, pp. 3-29, 2018.

ALVES, F. R. V. Situações Didáticas Olímpicas (SDOs): ensino de olimpíadas de matemática com arrimo no software GeoGebra como recurso na visualização. Alexandria: Revista de Educação em Ciência e Tecnologia, v. 13, n. 1, pp. 319-349, 2020. DOI: https://doi.org/10.5007/1982$\underline{5153.2020 \mathrm{v} 13 \mathrm{n} 1 \mathrm{p} 319}$

ALVES, F. R. V. Situação Didática Olímpica (SDO): Aplicações da Teoria das Situações Didáticas para o Ensino de Olimpíadas. Revista Contexto \& Amp; Educação, v. 36, n. 113, pp. 116-142, 2021. https://doi.org/10.21527/2179-1309.2021.113.116-142

ALVES, R. A alegria de ensinar. $3^{\text {a }}$ edição. ARS Poética Editora ltda, 1994.

ARTIGUE, M. Ingénierie didactique. Recherches en didactique des mathématiques, v. 9, n. 3, pp. 281-308, 1988.

ARTIGUE, M. (1996) “Engenharia Didáctica”, In: DIDÁTICA DAS MATEMÁTICAS. Brun, J. (Org.). Lisboa: Instituto Piaget.

ARTIGUE, M. Perspectives on design research: the case of didactical engineering. Angelika BiknerAhsbahs; Christine Knipping; Norma Presmeg. Approaches to qualitative research in mathematics education, Springer, pp. 467-496, 2014.

BADARÓ, R. L. Do Zero às Medalhas: orientações aos professores de cursos preparatórios para Olimpíadas de Matemática. 2015. Dissertação (Mestrado Profissional em Matemática em Rede Nacional - PROFMAT). Instituto de Matemática, Universidade Federal da Bahia, Salvador, 2015.

BAGATINI, A. Olimpíadas de Matemática, Altas Habilidades e Resolução de Problemas. Monografia (Licenciatura em Matemática) — UFRGS/Porto Alegre, 2010. Disponivel em:< https://www.lume.ufrgs.br/handle/10183/29144>. Acesso em: 18 dez. 2020.

BRASIL. Ministério da Educação. Base Nacional Comum Curricular. Brasília, 2018.

BROUSSEAU, G. Théorisation des phénomènes d'enseignement des mathématiques. 1986. 491 f. Tese (Doutorado) - Curso de Matemática, Université Sciences Et Technologies, Bordeaux, 1986.

CABARITI, E. A geometria hiperbólica na formação docente: possibilidades de uma proposta com o auxílio do cabri-géomètre. III Seminário Internacional de Pesquisa em Educação Matemática, 2006, São Paulo.

DOUADY, R. La ingeniería didáctica y la evolución de su relación con el conocimiento. Ingeniería didáctica en educación matemática, pp. 61-96, 1995. 
FIDELES, E. C. A OBMEP sob uma perspectiva de Resolução de Problemas. 2014. Dissertação (Mestrado Profissional em Matemática em Rede Nacional - PROFMAT) - Instituto de Ciências Exatas, Universidade de Brasília, Brasília, 2014. Disponível em:

〈https://www.repositorio.unb.br/bitstream/10482/17049/1/2014_EduardoCordeiroFideles.pdf $>$. Acesso em: 15 de dez. 2020.

LARA, M. T. V.; LOPES, M. R. C. M. Olimpíadas de Matemática: Uma estratégia de Ensino. 2013. Disponível em:

http://www.diaadiaeducacao.pr.gov.br/portals/cadernospde/pdebusca/producoes _pde/2013/2013_unicentro_mat_artigo_marcia_terezinha_veronese.pdf. Acesso em: 16 de out. 2020.

LIMA, M. L. O. Situações didáticas olímpicas para o ensino de sequências numéricas: um contributo da engenharia didática. 2019. 87 f. Dissertação (Mestrado) - Curso de Ensino de Ciências e Matemática., Universidade Federal do Ceará, Fortaleza, 2019. Disponível em: $<$ http://www.repositorio.ufc.br/bitstream/riufc/44173/1/2019_dis_mlolima.pdf $>$. Acesso em: $18 \mathrm{de}$ dez. 2020.

OBM. 2020. Olimpíada Internacional de Matemática. Disponível em: <https://www.obm.org.br/olimpiada-internacional-de-matematica/>. Acesso em 16 de dez. 2020.

OBMEP. 2020. Apresentação. Disponível em: 〈http://www.obmep.org.br/apresentacao.htm>. Acesso em 18 de dez. 2020.

OLIVEIRA, C. C. N. Olimpíadas de matemática: concepção e descrição de "Situações Olímpicas" com o recurso do software GeoGebra. 2016. Dissertação (Mestrado em Ensino de Ciências e Matemática) - Centro de Ciências, Universidade Federal do Ceará, Fortaleza, 2016. Disponível em: 〈http://www.repositorio.ufc.br/bitstream/riufc/21033/1/2016_dis_ccnoliveira .pdf $>$. Acesso em: 18 de dez. 2020.

PACHECO, J; PACHECO, M. F. A Escola da Ponte sob múltiplos olhares: palavras de educadores, alunos e pais. Porto Alegre: Penso, 2013.

PROFMAT. Mestrado Profissional em Matemática em Rede Nacional, 2020. Disponível em: https://www.profmat-sbm.org.br/. Acesso em: 16 nov. 2020.

RODRIGUES, G. R.; ALVES, F. J. C. Avaliação do uso de uma sequência didática no ensino de matrizes através da programação em blocos por um grupo focal. Revista de Estudos e Pesquisas sobre o Ensino Tecnológico, v. 5, n. 12, p. 30-50, 2019.

SANTOS, A. A.; ALVES, F. R. V. A Engenharia Didática em articulação com a Teoria das Situações Didáticas como percurso metodológico ao estudo e ensino de Matemática. Acta Scientiae, Canoas, v. 19, n. 3, pp. 447-465, maio/jun. 2017. Disponível em: 〈http://www.periodicos.ulbra.br/index.php/acta/article/view/2739/2373 > .Acesso em: $21 \mathrm{de}$ dez. 2020. 